\title{
A CALL FOR THE RADICAL RESTRUCTURING OF THE MINI-BUS TAXI INDUSTRY IN SOUTH AFRICA
}

\author{
L.J. Fourie ${ }^{1}$ and P.J. Pretorius ${ }^{2}$ \\ ${ }^{1}$ Barclays Capital, South Africa \\ louis.fourie@barcap.com \\ ${ }^{2}$ Department of Engineering and Technology Management \\ University of Pretoria, South Africa \\ pieter.pretorius@eng.up.ac.za
}

\begin{abstract}
This article examines the case for the formalisation of the mini-bus taxi industry in South Africa by applying the Theory of Constraints (TOC) thinking processes to the current situation. The paper endeavours to answer the question whether formalisation is essential for the survival of the industry. The most pressing issues in improving the performance of the industry is also highlighted, which presents a guide to investment decisions by government. Finally, the article comments on the government's proposed recapitalisation programme.

\section{OPSOMMING}

In hierdie artikel word die formalisering van die mini-bus taxibedryf in Suid-Afrika ondersoek met behulp van die Teorie van Knelpuntbestuur (TVK) denkprosesse. Die artikel stel dit ten doel om die vraag te beantwoord of formalisering noodsaaklik is vir die voortbestaan van die industrie. Verder word die mees kritieke aspekte vir verandering van die industrie uitgelig as riglyn vir investering deur die regering. Laastens lewer die artikel kommentaar op die regering se voorgestelde herkapitalisasie program.
\end{abstract}

\footnotetext{
${ }^{1}$ The author was enrolled for the MEng (Technology Management) at the Department of Engineering and Technology Management, University of Pretoria
} 


\section{INTRODUCTION}

A first-rate public transport system is one of the critical building blocks of a world-class economy. Even though South Africa boasts first-rate road infrastructure, public transport is limited in coverage and not really an attractive alternative to the private vehicle. The minibustaxi industry in South Africa has evolved to compete with the highly regulated and inefficient bus and rail services. The industry has displayed great levels of resilience and innovation in the face of shifting political and socio-economic conditions and has become the dominant mode of public transport in South Africa. However, the industry is plagued with violence, poor road safety and low financial margins. These problems and the associated deterioration of service levels pose serious reservations about the sustainability of the industry in its present form.

Furthermore, today the main competition of the taxi industry is not bus and train but rather the private vehicle. Therefore it is in the interest of the taxi industry to provide a service that can compare with the speed, efficiency and affordability of the private vehicle. Given the inefficiency-cost resulting from congestion on South African roads it is also in the interest of the government to promote public transport as an attractive alternative to private vehicle use. Therefore, government and the taxi industry will have to work together to provide a successful public transport system.

\section{OBJECTIVE OF THE RESEARCH}

Responding to the perceived problems, the government of South Africa set out to restructure the industry in terms of an ambitious recapitalisation plan. Under the recapitalisation programme taxi owners will receive subsidies to help them buy new 18 and 35-seater vehicles. However, the plan is already delayed by four years. Against the background of the present situation in the taxi industry, it is no doubt in the interest of all concerned parties (government, operators, drivers, commuters and the general public) that the formalisation of the industry be viewed afresh.

The aim of the research is to revisit the case for formalisation. Answers to the following two questions will be sought:

1. Is formalisation (i.e. regulation) essential for the survival of the industry?

2. Which issues are critical to the improved performance of the industry?

The taxi industry in South Africa has its roots in the informal economy; operating predominantly outside the legal, commercial and fiscal spheres of the economy. Despite its informal character, the taxi industry has become the preferred mode of public transport. Therefore, the regulation of the industry should not summarily be taken as a superior alternative. On the other hand startlingly poor road safety, poor security and low profit margins are threatening the survival of the industry. Mr Paul Browning of the Forum for Transformation in Transport, [1] reasons that "...the taxi industry has not managed to maintain and grow its investment" and that "its informal structure and rapid growth has disguised the fact that it is not economically sustainable". For this reason it is vital that areas of focus (to ensure the economic sustainability of the industry) be identified. 


\section{METHODOLOGY}

Research has been conducted on various aspects of the taxi industry. These studies have examined and highlighted the diverse problems limiting the performance of the industry. However, often the issues identified were symptoms rather than core problems. In order to get a better understanding of the intricate problems of the taxi industry, the Theory of Constraints (TOC) thinking processes were applied to the system (taxi industry). The TOC thinking processes is a suite of system level problem solving techniques aimed at finding the core problem that is underlying the poor performance of the system. Dr. Eliyahu Goldratt originated the TOC thinking processes with the intent "...to provide a systematic approach to enable people to create and implement the kinds of change that can also be considered improvement" [4]. The process uses a strict logical framework where cause and effect relationships are scrutinised to ensure logical arguments and conclusions.

The complete set of thinking processes can be applied to the system under investigation. However, because of limited space only the "Evaporating Cloud" diagram (ECD) will be presented here. An ECD will be constructed for the taxi industry in an attempt to expose the core problem of the system. This will then be used to work towards a solution to achieve the goal of a customer-focused and economically sustainable taxi industry.

\section{RETHINKING THE FORMALISATION OF THE INDUSTRY}

Scheinkopf [4] argues that "every problem can be described by a conflict". The ECD is a powerful tool that is used to "verbalise the core problem as a systemic conflict that is perpetuating the existence of undesirable effects". An ECD is constructed for the taxi industry in an attempt to uncover the core conflict and also evaluate how it is causing many of the problems experienced by the industry.

Essentially the taxi industry is a business, where forces of supply and demand will determine its future. The most cost-effective way (whether formal or informal) of serving their customers, will dictate the evolution of the industry. The discussion below should be followed in conjunction with Figure 1.

The overall objective of the taxi industry is to provide public transport to commuters in an economically sustainable manner [A]. In order to achieve the goal two necessary conditions must be met:

1. The industry must provide an attractive service [B]

2. The industry must be profitable [C]

As with any business in a free market, customers exercise their choice by buying the product that provides them with the best value for money. Here the product is transport and commuters will base their decision on the affordability, speed, reliability, safety and convenience of the service. Likewise, taxi operators will only participate in the industry if they can run profitable businesses. One might argue that this is not necessarily true of public transport as governments generally subsidise these services. However, governments worldwide are reducing their subsidies and privatising elements of public transport. There is increasing pressure on the providers of public transport to become self-sustaining. 
One can also argue that often taxis are the only alternative on offer in remote areas, as public transport might not be offered everywhere. Also, intimidation practices may exert pressure on commuters to make use of one specific mode of transport, without them exercising free choice. For the purpose of this research, areas which are subject to the first condition were not considered, where a subsidised public service is probably the only alternative. However, formalisation should eliminate 'mafia-like' territorial positioning by addressing the destructive competition issue.

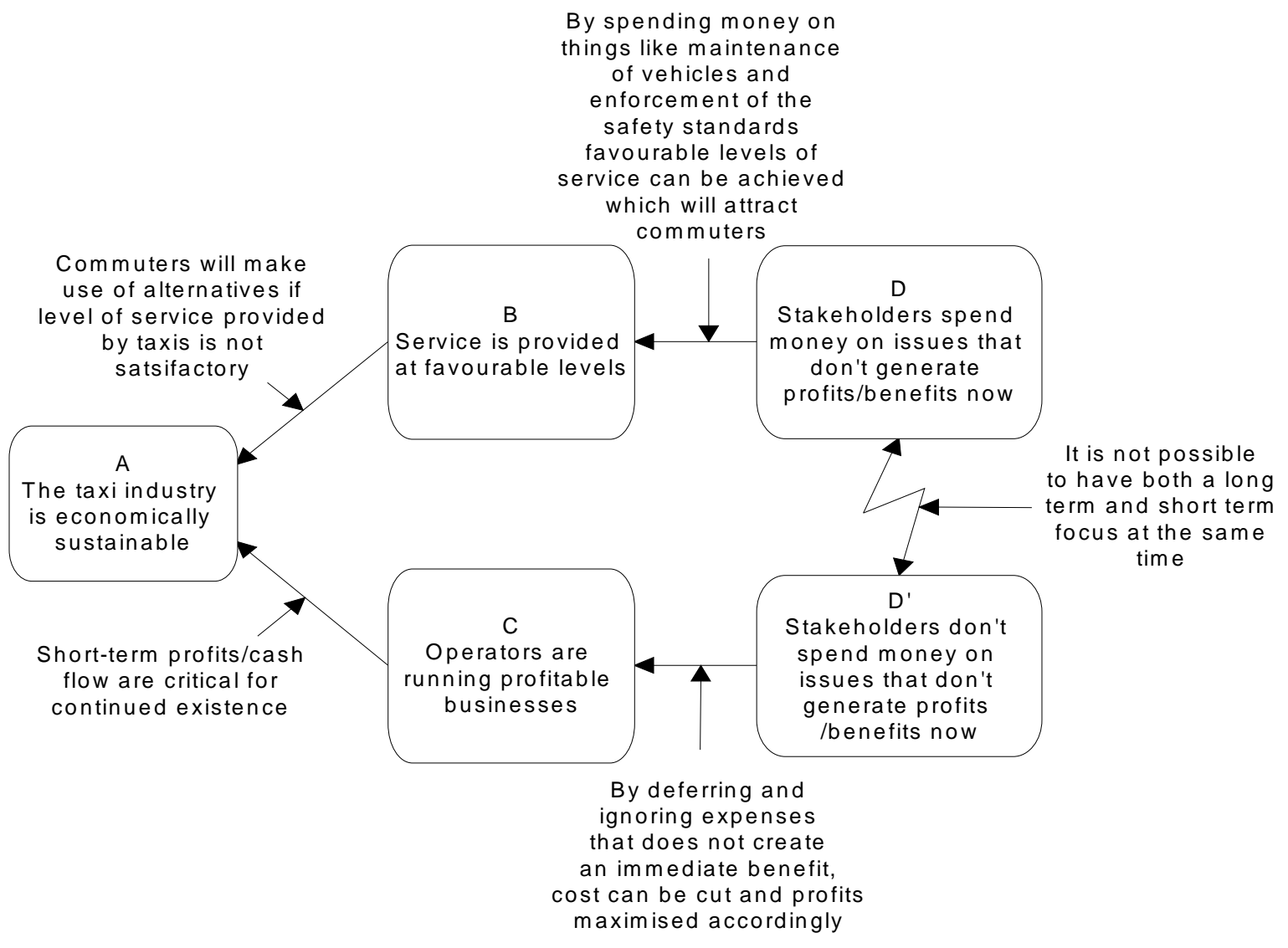

Figure 1: The evaporating cloud diagram for the taxi industry

For these two necessary conditions of providing an attractive service and being profitable to exist, certain prerequisites have to be met. To provide a safe, reliable and affordable service the industry requires re-investment and continuous upgrading to ensure safety and efficiency of the service is maintained. Thus, "stakeholders have to spend money on issues that won't generate immediate profits/benefits" [D]. On the part of operators, proper vehicle maintenance, good working conditions for drivers and improved financial management will fall into this category. In terms of the government's efforts restructuring the industry to eliminate destructive competition and enforcing safety standards can be viewed as actions that will provide benefits of a longer-lasting nature. This means taking a longer-term view and investing money that will not necessarily boost income now (it might well increase costs and reduce profitability in the short term) but will ensure the future survival of the industry. 
On the other hand, to maximise profitability the operators have to cut costs and keep reinvestment to a minimum and therefore "stakeholders should not spend money on issues that do not generate profits/benefits now" [D']. It is a well-known fact that no business can survive without a healthy cash flow. Controlling cost is absolutely crucial to warrant short-term profitability. What this means is that stakeholders focus primarily on actions that will secure short-term survival and any expense that does not have an immediate effect will be delayed or even disregarded. An example of this type of mindset is where only the bare minimum is spent on maintenance to keep vehicles running as well as minimising driver wages. Stakeholders are caught in a conflict between focusing on controlling cost to maximise profit and investing money on issues that will ensure and enhance their position as preferred public transport provider. Closer scrutiny of the South African taxi industry reveals that in actual fact the conflict is a classic example of short-term profitability vs. long-term sustainability.

The two prerequisites are apparently opposing and represent the conflict in the system. However, the two necessary conditions cannot exist without their associated prerequisites. Therefore, the conflict ultimately results in the common goal of an economically sustainable industry not being achieved. Thus the core problem is a systemic conflict that is propagating the existence of undesirable effects. But what is the cause of the conflict? By identifying what is causing the conflict the core problem can established. The answer lies in the fact that poor regulation of the industry has lead to overtraded routes and associated low cost-recovery of the operation, resulting in low profitability. Reduced profit margins encourage operators to skimp on maintenance and overload their vehicles - which they believe will boost their income. At the same time poor control has a direct impact on the other necessary condition of providing service at attractive levels. Appalling road safety and a high incidence of violence in the industry discourage commuters from using taxis and results in the industry losing market share.

Goldratt [6] states that "the Evaporating Cloud method does not strive to reach a compromise solution, rather it concentrates on invalidating the problem itself..." Rather than to try and find a compromise between long-term sustainability and short term profitability, one need only to realise that both these conditions are needed, e.g. improved service levels will not only ensure long-term sustainability [C], but the increased market share will also boost profitability [B]. Therefore, a structure that can support both these requirements needs to be pursued. Clearly, the current arrangement is not achieving this.

Thus the first question has been answered, namely: Is formalisation essential for the survival of the industry? The answer is obvious, the industry needs fundamental restructuring since the unregulated character is the underlying problem causing the system to not achieve its aim of providing an economically sustainable service.

\section{FRAMEWORK FOR AN IMPROVED INDUSTRY}

The framework that is being proposed presents a guide to investment decisions by government by identifying issues that should be addressed as a matter of urgency to transform the taxi industry into a high-quality public transport provider. It is beyond the scope of this paper to design a detailed implementation schedule but rather to provide a road map for the formalisation process and broad guidelines for policy formulation to improve the performance of the industry. 
From analysis of the evaporating cloud, it is concluded that the current state of the taxi industry calls for radical restructuring of the taxi industry within the larger transportation system to improve the overall efficiency of the system by giving due consideration to longterm economic sustainability, without jeopardising the short-term survival of the taxi industry. It is also imperative that to be successful, the new structure must eradicate destructive competition to improve profitability as well as enhance the level of service of taxi operation to reduce the gap in service standards between public and privately owned transport. Each requirement will now be discussed in greater detail.

\subsection{Eradication of destructive competition}

It has been observed that poor regulation has led to overtraded routes. The taxi industry came into being as a result of the convenience and speed that taxis provided were far superior to any other form of public transport. Initial high profits in an unregulated industry, as well as the profit potential by competing with other modes of transport, attracted many newcomers to the industry. Apart from the fierce competition that came into play between different taxi operators, taxis also started operating on high-demand corridors serviced by bus and rail. Taxi operators took this step in an attempt to boost their income as the original taxi routes have become so contested. This service replication reduced potential cost recovery of a route or mode, which is clearly a case of destructive competition, as defined by Shaw [5] as "competition between operators which reduces the potential for sustained cost recovery by individual operators, reduces the economy of scale benefits of higher-order modes and leads to the provision of poor and inconsistent service levels to users." This in turn led to violence due to the highly contested routes as well as reduced service and safety levels due to low profitability. Poor road safety and the unreliability of the service is becoming of progressing concern.

Destructive competition between the different modes is fundamental to the whole issue of low cost recovery and profitability. Shaw, from the CSIR's Roads and Transport Technology Division [5], describes the South African urban public transport system as "disjointed, uncoordinated" and "often using modes which are least suited to the associated demand conditions." Therefore, the logical first step will be to rationalise the public transport route network. The objective of rationalisation of the route network will consequently be to eradicate destructive competition and replace it with a route network that supports efficient operation and allows healthy competition. Existing problems that need to be overcome are:

- Distorted route network

- Service replication due to uncoordinated formal and informal modes

- A subsidy system that encourages distortion

The fact that formal (bus and rail) and informal (taxi) modes of transport have always been viewed separately has resulted in the current disjointed and uncoordinated structure of public transport in South African. The idea is to design an optimised arrangement - suited to the South African urban form - to remove service replication and improve potential for cost recovery on routes, while at the same time considering alternatives in the larger transport systems such as the Gautrain initiative. 
Once the optimal route network (in terms of lay-out and hierarchical structure) has been determined; the proposed configuration must be compared to the structure currently in place. Consolidating and co-ordinating existing operations provides the potential to improve the efficiency of the system. In some cases this might mean withdrawing a service where it has become inappropriate, either for reasons of oversupply or as a result of changing to a new route. In others it could involve the realignment of an existing route or combining overlapping services. This process will ultimately result in certain rail lines being abandoned, others being upgraded, new rail lines introduced (like the Gautrain initiative), mini-bus taxis being removed from certain high demand corridors and busses altering their function from lowdemand unconsolidated routes to corridor-based routes of high frequency. The restructuring will undoubtedly evoke high emotion and resistance from operators and therefore it is crucial that operators be consulted in the process and educated in terms of the benefits the new structure will hold for them. In addition, a well designed change management programme should also be implemented. In cases where services are removed assistance should be provided to employ the existing operators in other parts of the network or as a final resort they should be compensated. As with any other business, operators have invested time, capital and skill in their operations and their right to do business cannot summarily be dismissed.

At the same time, the Departments of Transport and Finance need to reach a resolution on the allocation of transport subsidies to provide clarity and direction as to what will happen in the future. Shaw [5] highlighted that "the method by which many services are currently subsidised support the destructive nature of competition." The idea here is to level the playing field for all transport operators and to bring subsidy allocation in-line with national transport objectives. A positive note is that the government in its Economic Vision 2014 has identified transport as one of the most important elements for increasing competitiveness. The authors are of the opinion that operations must ultimately be designed in a way that makes them non-reliant on subsidies as transport subsidies should rather be invested in wider enabling functions like:

- Infrastructure - efficient modal interchange facilities

- Maintenance contracts - to improve safety standards

- Education and training - i.e. financial management, business development, change management and customer service

- Pilot projects to investigate and test the viability of new vehicles/modes and to attract new business like tourists and students

Transport authorities should be pro-active and test the feasibility of alternative modal technologies in the South African context. Operators should be encouraged to be innovative and employ a mode that provides the right mix of capacity, operating cost and level of service to suit characteristics of the route they operate on. There should be incentives for operators to upgrade to higher order modes that will lower the overall system cost.

Finally, the whole process will be futile if there is no control to ensure everyone plays by the rules. Measures of monitoring and control should be put in place to protect the investments made by government and operators to rationalise the network. A creative means of service regulation is called for; one, which provides for limited but well exercised control and operator flexibility over the delivery of service. 
One of the great concerns among stakeholders is the potential job losses among drivers that the rationalisation exercise may bring about. Some services might have to be withdrawn where they are regarded as counter-productive to the efficiency of the network. However, regulating the industry will also create many new job opportunities in terms of monitoring and control, maintenance programmes etc. Depending on the success of the restructuring, market share of public transport operation may grow so that all these employees could be absorbed elsewhere, without necessarily increasing system cost.

Inevitably, the restructuring will not occur without a certain degree of resistance to change and a flare-up in violence will most probably be the result. Therefore, the whole process should be negotiated with all stakeholders in the public transport industry to prevent this. A central aspect of the negotiation will be to inform and educate operators and associations about the reason for the regulation, the long term benefits for them as well as the how the process will be rolled out. Taxi operators, owners, drivers as well as the users/commuters should especially be educated as to the reasons for the changes and the long-term benefits of the restructuring. Sufficient time should be allowed for the implementation of the process.

\subsection{Enhanced level of service}

The second part of delivering high-quality public transport is to deliver the service at improving levels of safety, reliability, affordability, speed and frequency. To increase modal share public transport should become an attractive alternative for private car users.

The latter three requirements, namely affordability, speed and efficiency will be significantly improved by the rationalisation of the route network discussed above. Improved efficiencies and profitability will make the service more affordable for commuters and frequencies can be increased. The fact that the network will be optimised will also reduce travel times.

In the current environment poor road safety is one of the main deterrents to the use of public transport. Accounts of accidents involving buses and taxis, often killing most passengers, are reported frequently. Hence, improving safety is instrumental in the whole exercise as this will change the perception in the minds of investors, commuters and the general public and will lay the foundation for expansion into new markets.

To see improvement in terms of road safety various aspects need to be addressed. The causes of poor road safety can basically be summarised as issues relating to:

- The vehicle

- Driving behaviour

- Enforcement

Only vehicles designed for mass transit ought to be used for public transport in South Africa. Vehicles used for public transport should be adequately maintained - it is no use making the capital layout for appropriate vehicles and not keeping them in a proper condition. If the government decides to subsidise the industry, this may well be one of the areas where subsidised maintenance contracts can be well employed to uphold safety standards. These measures will also have a positive impact on the reliability of the service. 
Related to this topic are safe loading and offloading practices. Both drivers and commuters should be educated in terms of safe boarding and alighting as well as the dangers of overloading. Proper load/alighting practices should be formulated and communicated to the general public to ensure that other drivers know what to expect from taxis and to be more accommodating to their presence on the road. Along with vehicle fitness regulation, general driving practice should also be reviewed. Being a taxi driver is a very responsible occupation and it should be treated as such. Advanced driving courses for taxi drivers will be essential to promote responsible driving. Together with improved driver training and testing enhanced labour relations are required. Long working hours and very low performance based wages are conducive to unsafe driving. Labour legislation specific to the taxi industry is needed as several of the provisions of the Labour Relations Act are not relevant to the minibus taxi industry. Road safety will not improve if the above-mentioned safety standards are not imposed. Therefore, transport authorities should strictly enforce vehicle fitness, loading practices and proper driving.

\section{FUTURE OUTLOOK OF THE INDUSTRY}

The first benefit of a consolidated and coordinated public transport network is that operation will be more efficient. The improved efficiency together with increased public transport modal share will lead to enhanced cost recovery resulting in increased profitability. Preliminary estimates by the Moving South African team have indicated that "modal optimisation on corridors could save up to $25 \%$ in costs" [3]. The creation of operating efficiencies and increased profitability might well be the single most important motivation for the whole restructuring exercise.

An additional advantage of the new structure is the fact that conflict and violence will be reduced. It was mentioned earlier that in the absence of state regulation, taxi associations often use violence as a means of protecting routes and operations. With a properly organised route network which is effectively monitored and controlled, this type of behaviour will become unnecessary and will greatly improve the security situation in the taxi industry.

The second requirement of the restructuring is to improve the level of service of taxi operation to reduce the gap in service standards between public and private transport. Moving South Africa's [3] vision for urban public transport in South Africa is the following: "By 2020, urban customers will be able to participate fully in the various activities of city life by using a public transport network that provides as much city-wide coverage as possible and which is affordable, safe, secure, fast and frequent." To accomplish this ambitious goal, service levels in the public transport industry will have to be improved dramatically. A transformed taxi industry has the best chance of achieving this.

The first positive spin-off from the improved levels of service will be that more people will use taxis as a mode of transport. Initially, the improved system might only attract the "captive" market (people who can't afford a private vehicle) but in time also groups of "selective" customers (people who can afford a car, but are willing to use public transport). The likes of students and tourists could easily be new target markets for taxi operators. These increased passenger numbers and vehicle occupancy will enhance the cost recovery of the operation. 
Poor road safety is one of the most alarming problems experienced by the taxi industry. The Moving South Africa [3] project established that the total cost of road accidents was around R12 billion in 1999. Although taxis are not responsible for all these collisions, improving taxis' safety will definitely add to safer road conditions. Improved levels of service also imply enforcing the safety standards that will contribute to first-rate road safety. By building up a good road safety record, operators will qualify for reduced insurance cost and finance charges. This will eventually contribute to a reduction in operating cost and thus increased profitability of the operation.

These higher levels of service will necessarily come at a price - better maintenance of vehicles, increased labour cost etc. Yet, with the increased profitability of their businesses operators should be able to meet these expenses.

The most encouraging fact is that because operators will be more profitable they will be able to reinvest in the industry - thereby constantly upgrading levels of service. There are other encouraging features of the formalisation as well, e.g. the fact that operators will qualify for bigger loans from banks, because of improved financial performance and lower risk profile. Also, the fact that security is improved will contribute to a bigger public transport modal share. These re-enforcing loops mean that the performance will continue to improve and the overarching objective of an economically sustainable taxi industry is achieved.

\section{COMMENTS ON THE RECAPITALISATION PROGRAMME}

The proposed recapitalisation programme is widely regarded as one of the most important exercises in restructuring public transport undertaken by any government in the world. Although the sweeping nature of the project is commendable there are two critical shortcomings in the programme:

- The first issue relates to the fact that the programme deals only with the replacement of the ageing taxi fleet, but does not address issues such as the destructive competition and route rationalisation. Furthermore, the recapitalisation programme will revamp the taxi fleet through a capital injection of approximately R4 billion - but the plan does not deal with the consolidation and coordination of other modes of public transport. In research done in Latin America, Figueroa et al [5] found that capital-intensive public transport projects without the coordination and effective institutional and regulatory responses has had disastrous effects on the cost-recovery of the new systems; "One of the key reasons identified for poor system performance was linked to the unwillingness on the part of government to deal effectively with issues of destructive competition between rail and other modes"

- The second problem with the proposed plan is that it is "largely driven by safety considerations" [2]. Although safety is a very important aspect of improving levels of service - it is not the only one. Also an industry driven by anything other than profit would most probably become reliant on subsidies and will therefore not be self-sustaining. Other than subsidised vehicles, the programme does not indicate how profitability will be enhanced. 


\section{CONCLUSION}

The affirmation of the fact that the informal and unregulated character of the taxi industry is threatening its survival, indisputably calls for the formalisation of the industry. The formalisation will facilitate the integration of the taxi industry with other modes of transport as well as the formal economy. The process will also allow government to obtain a degree of control over the industry to provide effective transportation planning and oversee the safety of the public. The new structure will offer commuters and current non-users in South Africa the prospect of genuinely safe, secure and reliable public transport for the first time. It should also be acknowledged that the TOC thinking processes is a very powerful suite of tools that allow the researcher to develop robust solutions for complex problems. A final thought to encourage the call for fundamental restructuring can be drawn from the words of Albert Einstein: "the significant problems we have cannot be solved at the same level of thinking with which we created them."

\section{REFERENCES}

[1] Browning, P. (2001) Wealth on Wheels? The minibus-taxi, economic empowerment and the new passenger transport policy. South African Transport Conference, July 2001.

[2] Khosa, M. and Browning P. (2001). Wealth on Wheels? Unpublished book.

[3] Moving South Africa, Action Agenda (1999). A 20-Year Strategic Framework for Transport in South Africa. Issued by the Minister of Transport and the National Department of Transport.

[4] Scheinkopf, L.J. (2000) Thinking for a Change: Putting the TOC thinking processes to Use, Boca Raton: St. Lucie Press, 2000.

[5] Shaw, A. (1998). Fundamental Restructuring of the Planning, Management and Operation of Urban Public Transport Networks. CSIR, Pretoria.

[6] Smith, M. and Pretorius P.J. (2002) Applying the theory of constraints to increase economic value added: Part 2 - Implementation. South African Journal of Industrial Engineering, 13(2): 71-80. 
